\title{
Sistema patriarcal, artículo de importación colonial en los Andes
}

Lucía ALVITES SOSA

\begin{abstract}
RESUMEN
El patriarcado no existía en los Andes previo a la llegada de los colonialistas europeos, llegó junto con la colonia como parte del eje de dominación. Y, aunque hoy es ya una pesada herencia propia, existe también una memoria ancestral de otros órdenes de género posibles. En tal sentido, indagamos sobre los orígenes de las relaciones de género en América Latina pre colonial, específicamente en el Tahuantinsuyo, como expresión sintética acumulada de miles de años previos de nuestras culturas prehispánicas.
\end{abstract}

PALABRAS CLAVE: Género, colonialidad, patriarcado, Tahuantinsuyo.

\section{Patriarchal system of colonial import article in the Andes}

\begin{abstract}
Patriarchy was an import in the Andes, he came together with the colony as an axis of domination. And, although today it is a heavy own inheritance, there is also an ancestral memory of other possible orders gender. In this regard, we investigate the origins of gender relations in pre colonial Latin America, specifically in the Tahuantinsuyo, as accumulated synthetic expression of thousands of previous years of our prehispanic cultures.
\end{abstract}

KEYWORDS: Gender, Coloniality, Patriarchy, Tahuantinsuyo. 
E I sistema sexo-género es una categoría teórica acuñada por la antropóloga estadounidense Gayle Rubin (1989), que esencialmente refiere a la dinámica de atribución de características y de adjudicación de roles, a partir del sexo masculino y femenino construido como imaginario social y cultural. Es decir, si eres hombre tendrás determinadas atribuciones y mandatos, si eres mujer, otras. Las teorías de género y los estudios feministas han llamado, al específico sistema sexo-género que hoy tenemos, patriarcado, que en palabras de Rosa Cobo (2005) se define como: "un sistema social en el que el género es un principio de jerarquización que asigna espacios y distribuye recursos a varones y mujeres" (250).

El sistema sexo-género aparece como un instrumento conceptual de los movimientos sociales y académicos de género, feministas y antipatriarcales, representando simultáneamente una crítica teórica y una resistencia política, que devela y denuncia la pretendida naturalización de los estereotipos, mitos y prejuicios construidos para el dominio del hombre y lo masculino sobre lo femenino y la mujer en la cultura moderna occidental.

Su desarrollo se abrió paso hasta oficializarse en la academia y el sistema internacional de Derechos Humanos, aunque todavía queda mucho por hacer para que opere plenamente a nivel de las políticas públicas y de las prácticas sociales realmente existentes, tras siglos de patriarcalismo y discriminación hacia la mujer.

Esta realidad objetiva e innegable para las ciencias sociales nos hace preguntarnos ¿Cómo llegamos a esto? Para ser más precisos, ¿cuándo y cómo se inició el patriarcado en nuestros territorios? ¿Siempre vivimos bajo este sistema sexo género? ¿Y si no fue así, qué había antes en América Latina?

Una de las críticas que se han incubado dentro de los estudios de género y feministas es que muchas veces han partido de un análisis que pretende universalizar un tipo de mujer que es específicamente occidental. Judith Butler (2007) lo expone así:

Esa manera de hacer teoría feminista ha sido cuestionada porque intenta colonizar y apropiarse de las culturas no occidentales para respaldar ideas de dominación muy occidentales, y también porque tiene tendencia a construir un "tercer mundo" o incluso un "oriente", donde la opresión de género es sutilmente considerada como sintomática de una barbarie esencial, no occidental $(49,50)$.

Es en este marco que se plantea este trabajo que tiene como objetivo buscar los orígenes de las relaciones de género en América Latina, indagar si hubo un antes del sistema sexo género patriarcal $y$, si lo hubo, qué fue. Creemos que ese intento puede llevarnos a comprender y practicar mejor una sociología de género en el Perú. Para lograr nuestro objetivo nos remontaremos hasta el Tahuantinsuyo como expresión sintética acumulada de miles de años previos de nuestras culturas prehispánicas.

\section{6/ REVUSTA DE SOCOLLOGíA 26}


Uno de los mitos más importantes sobre el origen de la sociedad inca es el de los Hermanos Ayar: Ayar Uchu, Ayar Cachi, Ayar Mango y Ayar Auca; quienes junto a sus cuatro hermanas: Mama Ocllo, Mama Huaco, Mama Ipacura y Mama Raua inician un peregrinaje con el propósito de encontrar un lugar indicado donde establecerse; según varios cronistas Mama Huaco era una de los liderazgos de los hermanos Ayar, y fue ella quien arrojó la vara que señalaría el lugar donde se establecerían y fundarían el Estado; también se cuenta que cumplió un rol fundamental como guerrera conduciendo ejércitos. Su mismo nombre le da sentido a estos mitos, ya que la palabra Huaco en aymara se refiere a una mujer varonil y libre. Como bien señala la historiadora María Rostworowski (1988):

No interesa saber si los hechos fueron verídicos o míticos, lo importante es analizar la estructura social que la leyenda sugiere. En esta Coya hallamos a la mujer tomando parte activa en la conquista del Cusco, luchando junto a los varones y capitaneando un ejército, lo que ilustra la situación femenina en un tiempo mítico, y el nivel concedido a su posición social ( 33-35).

Este mito encierra la idea de que la mujer tenía la posibilidad de participar e intervenir de forma relevante en situaciones públicas de suma importancia. Es más, siendo sujeto de acción en el plano militar. Estamos hablando que a mediados del siglo XV en los territorios que conformaban el Tahuantinsuyo, que hoy representan varios países de la región, las mujeres eran parte de los hitos históricos.

La conclusión no es menor, porque a través del mito podemos resolver que se expresa una realidad social y en ella un sistema sexo género radicalmente distinto al de occidente. En esta misma época en Europa se realzaba un discurso religioso que estuvo íntimamente ligado a una práctica ampliamente extendida en el tiempo (duró cuatro siglos) y en sus territorios, nos referimos a la conocida caza de brujas. Las brujas eran las mujeres que practicaba otro tipo de conocimiento, es decir eran parteras, sanadoras o no pertenecían a la religión oficial. Además, el discurso religioso daba cuenta en su mito fundacional, el génesis, que la mujer originaria, Eva, es literalmente apenas un apéndice de Adán, el hombre; más aún, todo lo negativo surge de ella, la mala intención, la pérdida y la culpa (Fernández, 1993).

Del mito sobre el origen de la sociedad Inca, última administración de un orden social complejo formado por centenares de diversos pueblos ancestrales de los cuales descendemos, podemos ver dos entradas que nos permiten aportar a la reconstrucción de una memoria doblemente negada, una historia bi postergada. Nos referimos simultáneamente a la memoria de los pueblos indígenas, afrodescendientes, mestizos, criollos, latinoamericanos. Y a la de las mujeres dentro de ella. Doblemente negadas entre los negados, doblemente vencidas, silenciado más aún su protagonismo, in- 
concebible e incomprensible para los que hasta ahora han contado nuestra historia oficial, e incluso a veces alternativa.

Esta situación muchas veces nos ha impedido comprender los roles de mujeres y hombres antes de la llegada de Europa a nuestro continente. Por eso, encontramos que a veces se ha mostrado con acierto el patriarcalismo, pero sin poder superar el más sutil e internalizado colonialismo eurocéntrico. Otras, al revés, se trabaja exitosamente por desnudar la colonialidad pero no llega a cruzarse con el análisis de género.

Siguiendo el rastro histórico de nuestras relaciones de género, comprobaremos que el mito de Mama Huaco no es una excepción, una fábula descontextualizada, todo lo contrario expresaba una dinámica más global. En el Tahuantinsuyo, también se señala otro mito, se trata de las piedras Pururauca, las cuales, en medio de la batalla, se convertían en míticos guerreros invencibles, otorgando la victoria a los incas. "Entre las piedras pururauca, en el Cusco adoraban especialmente a una llamada Tanancuricota que era venerada por ser una mujer que apareció junto con los legendarios soldados; con ella lo femenino quedaba comprendido en la gesta guerrera" (Rostworowski, 1988, 131).

Además, en el Tahuantinsuyo era ley que"todos los hijos e hijas de un Curaca (autoridad política administrativa regional) podían pretender al poder", siendo la condición principal para acceder a estos cargos de poder la capacidad y habilidad, independiente de su sexo (Rostworowski, 1988, 139). Fueron numerosas las mujeres en estos cargos de poder; es el caso de la Curaqueza Contarhuacho, señora de seis guarangas (mil unidades domésticas) de Huaylas (Rostworowski, 1988, 141, 184, 191). Otro cargo de alto poder, el de sacerdote, era también ejercido por mujeres, sacerdotistas, algunas de ellas famosas, "como aquella del ídolo de Apurímac, que prefirió lanzarse al abismo antes de caer en manos de españoles" (Rostworowski, 1988, p. 208). Se sabe que en el sistema de herencia del mundo andino la mujer podía tener acceso a la propiedad de sus propios bienes y heredar a sus descendientes y no a los del marido (Rostworowski, $1988,244)$, cuestión que en el sistema occidental fue bandera de lucha todo el siglo XX y se logró muy recientemente en nuestra América Latina.

Otra de las banderas de lucha de las mujeres en la cultura occidental es la de la igualdad en el lenguaje español, que no cuenta formalmente con una palabra para designar a hombres y mujeres, invisibilizando a las mujeres en categorías plurales masculinas, actualmente se buscan fórmulas auxiliares para suplir esta ausencia; curiosamente, en el Runa Simi (idioma "general" del Tahuantinsuyo, derivado del quechua), todas las categorías de ciclo de vida estaban distinguidas en femenino y masculino (Rostworowski, 1988, 293-302).

Estas evidencias de un sistema sexo género particular e inédito, propio de las culturas latinoamericanas ancestrales, aparece por todo el continente. Es el caso de la Gaitana,

\section{8/ RELUSTA De SOCOLOOGÍA 26}


indígena huila de la actual Colombia, quien comandó la federación Pijao de diversos pueblos indígenas, derrotando militarmente a los españoles y ajusticiando al gobernador Pedro de Añasco, cuyos crímenes contra la población indígena le valieron fama, siendo convertida por los cronistas españoles en el símbolo de todo lo negativo y perverso que el patriarcalismo occidental atribuyó a lo femenino (Osorio, 1997, 25-44).

También el de la Janequeo, nombre castellanizado de Anuqueupu, originaria de la actual Villa Rica, en el sur de Chile, quien llegó a ser Inan Toqui, comandante general del ejército popular de resistencia mapuche, llegando a derrotar completamente a los españoles en 1585 y 1586 (Gavilán, 2007, 70-73), bajo el lema registrado por los cronistas: "no creas lo que digo sino mira lo que hago" (Gavilán, 2007, 71). Y no era una excepción entre los Mapuche:

En el ejército popular mapuche, también combatían las mujeres, llegaron a tener escuadrones completos de mujeres, diestras en el caballo y el uso de la lanza y la flecha, expertas en guerra de dispersión, espionaje y las tareas de la retarguadia... Guacolda luchaba en el mismo escuadrón de Lautaro y otras miles de lamgens (hermanas) lo hicieron y aún lo hacen en esta larga lucha del pueblo mapuche. (Gavilán, 2007, 64)

Para el pensamiento europeo que en esos años recién salía del sexocidio más grande de su historia, el crimen masivo contra las mujeres para someterlas por el terror, con lo que fue la caza de brujas que duró hasta entrada la Edad Moderna (Fernández, 1993), era imposible reconocer al género femenino participando a la par de los hombres, y menos aún al mando de ellos en contextos de poder o desgarramientos históricos.

No afirmamos que el sistema sexo género de los pueblos originarios de América Latina sea el ideal o que estuviera libre de contradicciones y relaciones de dominación, lo que sí evidenciamos es que se trata de uno absolutamente inédito y original, no reductible al de Europa occidental pretendido como modelo único, universal.

Durante la colonia española, surge la figura temprana y pionera de Sor Juana Inés de la Cruz, defendiendo su derecho de ser mujer e intelectual, en una época, segunda mitad del siglo XVII, cuyo orden social sometía a las mujeres criollas blancas a dos únicas opciones de vida, ser esposa sumisa y pasiva, o ser religiosa de la iglesia católica en el convento. A temprana edad, aprende a leer a escondidas, desde los ocho años sueña con ingresar a la primera universidad en México, y desde esa edad también comprende "que el mayor obstáculo a su deseo de saber era su género" (c.p. Scott, 1997, 49). En esa encrucijada, opta por el convento, único espacio posible para desarrollar una obra poética e intelectual tan rica y valiosa como crítica de los convencionalismos patriarcales: "... ¿O cuál es más de culpar, / aunque cualquiera mal haga: / la que peca por la paga / o el que paga por pecar?" (c.p. Scott, 1997, 56). 
En 1871, liderada por José Gabriel Condorcanqui, Túpac Amaru II, se produce la más grande rebelión anticolonial en Suramérica, que llegó a abarcar, a lo largo de dos años, territorios de siete de los actuales países (Perú, Bolivia, Ecuador, Colombia, Venezuela, Argentina y Chile), y que tuvo repercusiones en lugares tan distantes como Panamá y México. Superando largamente la atrasada cultura machista de los civilizados europeos de la época, en ella las mujeres jugaron con plena igualdad un rol crucial en el movimiento.

Los muy temidos batallones de mujeres que, según los partes de guerra españoles, eran más feroces que los hombres, fueron un instrumento estratégico en la lucha. Pero ellas estuvieron al mando, no solo de mujeres, sino de hasta cinco mil hombres, siendo mandos, combatientes y mártires de la epopeya, como en la batalla del Cerro Puquinacancarí, librada el 19 de mayo de 1781, y comentada así en los informes españoles:

\begin{abstract}
Y sin embargo de no llegar a 100 los enemigos hicieron una obstinada y bárbara defensa... Pero ellos lejos de intimidarse con la inmediación de las tropas que se dirigían al ataque, se mantuvieron obstinados, sin pensar más que en morir o defender el puesto que ocupaban, con la mayor intrepidez y osadía... y viéndose ya sin recurso, algunos se despeñaron voluntariamente, y entre los otros una mujer con un niño a las espaldas. Los pocos que se cogieron vivos se ajusticiaron; una mujer prisionera se tendió voluntariamente sobre un cadáver y viendo que tardaban en matarla, levantó la cabeza y dijo por qué no la mataban. (Mariscal José del Valle. Parte de Guerra. C.p. Jimenez, 2007, 72-73)
\end{abstract}

Un testigo realista de la insurrección registró el radical carácter subversivo que representaban estas mujeres para los roles socialmente asignados a ellas:"Finalmente esta provincia está en una confusión infernal... Solamente se ve y se sabe de crímenes, prueba de lo cual es la niñería que ha permitido nombrar mujeres como capitanes" (José Tapia, sacerdote realista y vicario general de los Ilanos de Casanare, actual Venezuela. Informe al gobierno colonial. 10 de julio. 1781. C.p. Jiménez, 103.).

Pero no sólo en lo militar rompieron roles de subordinación femenina, sino que además fueron relevantes organizadoras e ideólogas, con mando sobre extensas regiones y poblaciones, como Micaela Bastidas, esposa de Tupac Amaru II, quien era:

Lo que diríamos ahora la jefa del ejército indio. Era ella la que reunía los contingentes de campesinos que llegaban al Cuartel General; ella la que dictaba las ordenes, salvoconductos, cartas, proclamas, ella la que veía por la seguridad del Inca; la que reflexionaba y atingía la acción... la que cuando urgía se ponía a la cabeza de los guerrilleros nativos y salía a pelear y vencer. (Barrionuevo, 1976, 112)

\title{
200/REVISTA DE SOCOLOOGÍA 26
}


También Tomasa Tito Condemayta, curaqueza (autoridad política administrativa regional) de Acos, Bartolina Sisa, Úrsula Pereda, Cecilia Escalera, Gregoria Apaza, Marcela Castro, Margarita Condori, Manuela Tito, Antonia Castro, Agustina Ayma, Catalina de Salas y Pachakuti, Francisca Herrera, Manuela Beltrán, y centenares de mujeres, indias, mestizas y criollas, con un promedio de 26 años de edad, quienes rompían desde su vida misma, su práctica cotidiana, junto con la dominación colonial, la de los prejuicios y roles patriarcales asignados por la colonialidad patriarcal.

En la línea de vindicación de los derechos de las mujeres podemos encontrar a Francisco de Miranda, precursor de la independencia, quien escribía lo siguiente:

Yo le recomiendo una cosa de mi parte, sabio legislador, y esa es las mujeres... ¿Por qué en un gobierno democrático la mitad de los individuos no están representados directa o indirectamente; a pesar de que están igualmente sujetos a la misma severidad de las leyes que los hombres han hecho a su voluntad? ¿por qué al menos no son ellas consultadas sobre las leyes que las conciernen más directamente, como son las del matrimonio, el divorcio, educación de las hijas, etc.? Yo le confieso, que todas esas cosas me parecen usurpaciones escandalosas... (Carta de Francisco Miranda a Jerôme Pétion. 26 de octubre de 1792. C.p. Bohórquez, 2006, 349-350).

Miranda sostuvo constantemente esta lucha, y ella cayó en la más absoluta incomprensión y silenciamiento, lo prueban los siguientes pasajes de la misma carta:

Si yo tuviera aquí mis papeles, encontraría unas observaciones que he hecho sobre este mismo asunto hablando con algunos legisladores de América y Europa, quienes no me dieron nunca ninguna razón satisfactoria, y la mayor parte de ellos convinieron en que se trata de una injusticia (Carta de Francisco Miranda a Jerôme Pétion. 26 de octubre de 1792. C.p. Bohórquez, 2006, 350)

Pero Miranda no sólo reflexionó y propuso sobre la igualdad de derechos de las mujeres, también la incorporó en su práctica de lucha independentista. Cuando su precursor desembarco militar independentista en Coro, Venezuela, del año 1806, tres mujeres estuvieron entre las diez personas de la región procesadas por conspirar en apoyo de Miranda y su malograda incursión. Durante la Primera República Venezolana, en 1811, en la Sociedad Patriótica, la primera organización política antecedente de los Partidos Revolucionarios modernos, cuya creación es atribuida a Miranda y Bolívar, no sólo encuentran membresía los criollos revolucionarios, sino también, por primera vez en siglos, los excluidos y despreciados: los pardos (mestizos, indígenas y negros) y las mujeres (Bohórquez, 2006, 272-302). 
En esa misma línea podemos encontrar a Simón Rodríguez, el maestro de Bolívar, ya en 1826, como ministro de educación de la naciente Bolivia fue acusado de loco y degenerado por la oligarquía, por plantear, además del bilingüismo escolar indígena, las escuelas mixtas y porque "daba instrucción y oficio a las mujeres para que no se prostituyesen por necesidad, ni hiciesen del matrimonio una especulación para asegurar su subsistencia" (Rodríguez, 1990 [1828], 254).

Matrimonio por sobrevivencia es justamente el de Manuela Sáenz, y más tarde el de Flora Tristán. Manuela es popularmente conocida como la amante y fiel compañera de Simón Bolívar, sin entender que ella era una referencia en sí misma, como persona, y no del otro siempre masculino, restándole así su personalidad propia e independiente. Poco se sabe que Manuela subvirtió el rol social que estaba asignado a su género - y casta, por ser ilegítima - y lo hizo antes de conocer y enamorarse de Bolívar, con su participación activa y decisiva en la libertad de nuestro continente, asumiendo tareas políticas de conspiración, y militares en donde por su desempeño se le otorgó la Orden del Sol que se la dio el mismo San Martín en 1822. Esta Orden era una muestra del programa revolucionario de San Martín, inspirada en la memoria ancestral andina, y destinada a proteger con pensiones de por vida y hereditarias a los más destacados patriotas y sus familias, que habían sacrificado su vida y fortunas por la causa revolucionaria, de la venganza oligárquica que, finalmente, sí condenó a la miseria y el olvido a casi todos ellos. Era, además, una medida simbólica revolucionaria para remplazar el privilegio nobiliario y del dinero por el del mérito en la causa libertaria. El carácter subversivo del género para la época de esta distinción otorgada a Manuela lo registra Bartolomé Mitre, historiador y presidente de Argentina, organizador de la república oligárquica, etnocida y centralista, y declarado enemigo de San Martín y Bolívar, quien se escandaliza de la medida por considerarla propia de indígenas y por incluir a las mujeres:"como complemento de ese plan de aristocracia indígena, hizo extensivos a la mujer sus honores y privilegios" (C.p. Galazzo, 2000, 367). Manuela ascenderá a coronela por su valor como lancera a caballo en la batalla de Ayacucho que consagró la libertad de América.

Con esa misma firmeza con la que hizo suya la lucha por la libertad y la integración latinoamericana, ella logró en su vida personal romper con las ataduras sociales que exigían a la mujer ser esposa sumisa y pasiva, casada desde muy joven por arreglo de su padre con el médico inglés Jaime Thorne, Manuela al enamorarse de Bolívar asumió sin prejuicio y con orgullo su amor rebelde, prueba de ello es una carta que le envía al que fue su esposo donde le dice: "Me cree Ud. menos honrada por ser él mi amante y no mi marido? ¡Ah! Yo no vivo de las preocupaciones sociales" (C.p. Ortiz, 1997. P. 100), palabras precursoras para su tiempo; sin embargo, casi desconocidas por las feministas y estudiosas del género en América Latina. 
Y no fue la única. Son numerosas las mujeres en toda nuestra América que al mismo tiempo que subvirtieron la dependencia colonial, lo hicieron también con el patriarcalismo hegemónico. Policarpa Salavarrieta, experta en inteligencia para la causa de la primera independencia en la actual Colombia; Juana Azurduy, jefa guerrillera patriota del Alto Perú hoy Bolivia; Rosa Campusano patriota independentista en el actual Perú; Gertrudis Bocanegra patriota y mártir del actual México y centenares más, que podrían llenar innumerables páginas con aportes precursores, con protagonismos contra patriarcales, a medio enterrar todavía, pendientes por descubrir. Estas mujeres y sus historias serán los antecedentes del feminismo latinoamericano.

Como vemos encontramos un hilo conductor, si se quiere decir de otra forma, el código genético, que nos evidencia que el patriarcado fue un artículo de importación en nuestras latitudes. Y que, aunque hoy es ya una pesada herencia propia, existe también una memoria ancestral de otros órdenes de género posibles.

Esta realidad nos lleva a dos tareas académicas desde la sociología. Una, estudiar e identificar la línea histórica de los sistemas sexo género que hemos tenido, enfocándonos en una epistemología que nos ayude a mirarlos sin etiquetas muchas veces sacramentadas por la academia pero extrañas y distantes a las realidades a las que nos queremos aproximar. Dos, proponer nuevas ramas de investigación desde los estudios de género que nos permita peruanizar este enfoque, permitir una arqueología de lo silenciado, como insumo que alimente propuestas de hoy y de mañana.

\section{Referencias bibliográficas}

COBO, Rosa (2005). El género en las ciencias sociales. España: Cuadernos de Trabajo Social. BUTLER, Judith (2007). El género en disputa. España: Paidós.

BOHÓRQUEZ, Carmen (2006). Francisco de Miranda. Precursor de las independencias de América Latina. Venezuela: Fundación editorial el perro y la rana.

FERNÁNDEZ, Ana María (1993). La mujer de la ilusión. Pactos y contratos entre hombres y mujeres. Argentina: Paidós.

GalAzzo, Norbert (2000). Seamos libres y lo demás no importa nada. Vida de San Martín. Argentina: Colihue.

GAVILÁN, Víctor (2007). La nación Mapuche. Puelmapu Ka Gulumapu. Chile: Ayun.

JIMÉNEZ, Ricardo (2007). El largo parto de un pensamiento propio. Historicidad y generalización ahistórica en América Latina. Bolivia: RUTA - C. E. Mariátegui

ORTIZ, Lucía (1997). Genio, figura y ocaso de Manuela Sáenz. En: Las desobedientes. Mujeres de Nuestra América (Panamericana Editor). Colombia: Panamericana. 
OsORIO, Betty (1997). La Gaitana: mito de autonomía y resistencia. En: Las desobedientes. Mujeres de Nuestra América (Panamericana Editor). Colombia: Panamericana.

Rostworowski, María (1988). Historia del Tahuantinsuyo. Perú: Instituto de Estudios Peruanos.

RUBIN, Gayle (1989). Reflexionando sobre el sexo: notas para una teoría radical de la sexualidad. En: Vance, Carole (comp.). Placer y peligro. Explorando la sexualidad femenina. Madrid: Revolución.

ScotT, Nina (1997). La inmolación intelectual de Sor Juana Inés de la Cruz. En: Las desobedientes. Mujeres de Nuestra América (Panamericana Editor). Colombia: Panamericana. 